\title{
Proteomic profiling of von Hippel-Lindau syndrome and multiple endocrine neoplasia type 2 pheochromocytomas reveals different expression of chromogranin B
}

\author{
Frederieke M Brouwers, Sven Gläsker ${ }^{1}$, Amanda F Nave, Alexander \\ O Vortmeyer ${ }^{1}$, Irina Lubensky ${ }^{1}$, Steven Huang ${ }^{1}$, Mones $S$ Abu-Asab ${ }^{2}$, \\ Graeme Eisenhofer ${ }^{3}$, Robert J Weil ${ }^{1,4}$, Deric M Park ${ }^{1}$, W Marston Linehan ${ }^{5}$, \\ Karel Pacak and Zhengping Zhuang ${ }^{1}$
}

\author{
Reproductive Biology and Medicine Branch, National Institute of Child Health and Human Development, National Institutes of Health, \\ Bethesda, Maryland, USA ${ }^{1}$ Surgical Neurology Branch, National Institute of Neurological Disorders and Stroke, National Institutes of \\ Health, 10 Center Drive, Room 5D37, Bethesda, Maryland 20892, USA \\ ${ }^{2}$ Laboratory of Pathology, Center for Cancer Research, National Cancer Institute, National Institutes of Health, Bethesda, Maryland \\ 20892, USA \\ ${ }^{3}$ Clinical Neurocardiology Section, National Institute of Neurological Disorders and Stroke, National Institutes of Health, Bethesda, \\ Maryland 20892, USA \\ ${ }^{4}$ Brain Tumor Institute, Cleveland Clinic Foundation, Cleveland, Ohio 44195, USA \\ ${ }^{5}$ Urologic Oncology Branch, National Cancer Institute, National Institutes of Health, Bethesda, Maryland 20892, USA \\ (Requests for offprints should be addressed to Z Zhuang; Email: zhuangp@ mail.nih.gov)
}

\begin{abstract}
Pheochromocytomas are catecholamine-producing tumors that can occur in the context of von Hippel-Lindau syndrome (VHL) and multiple endocrine neoplasia type 2 (MEN2). Pheochromocytomas in these two syndromes differ in histopathological features, catecholamine metabolism, and clinical phenotype. To further investigate the nature of these differences, we compared the global protein expressions of 8 MEN2A-associated pheochromocytomas with $11 \mathrm{VHL}$-associated pheochromocytomas by two-dimensional gel electrophoresis proteomic profiling followed by sequencing and identification of differentially expressed proteins. Although both types of pheochromocytoma shared similarities in their protein expression patterns, the expression of several proteins was distinctly different between VHL- and MEN2A-associated pheochromocytomas. We identified several of these differentially expressed proteins. One of the proteins with higher expression in MEN2-associated tumors was chromogranin B, of which the differential expression was confirmed by western blot analysis. Our results expand the evidence for proteomic differences between these two tumor entities, and suggest that VHL-associated pheochromocytomas may be deficient in fundamental machinery for catecholamine storage. In light of these new findings, as well as existing evidence for differences between both types of pheochromocytomas, we propose that these tumors may have different developmental origins.

Endocrine-Related Cancer (2007) 14 463-471
\end{abstract}

\section{Introduction}

Pheochromocytomas are catecholamine-producing tumors arising in the adrenal gland or sympathetic ganglia, where they are referred to as paragangliomas (Lenders et al. 2005). These tumors can occur as a sporadic entity or in the context of several hereditary syndromes, such as von Hippel-Lindau syndrome (VHL), multiple endocrine neoplasia type 2 (MEN2), neurofibromatosis type 1 (NF1), and familial paragangliomas. The genes associated with these inherited pheochromocytomas respectively are the VHL tumor suppressor gene, the rearranged during transfection (RET) proto-oncogene, the NF1 gene, and the genes encoding for subunits $\mathrm{B}$ and $\mathrm{D}$ of the succinate dehydrogenase gene (SDHB and SDHD; Riccardi 1981, Neumann et al. 2002a,b, Bryant et al. 2003). 
Pheochromocytomas associated with VHL disease and MEN2 have distinct histopathological (Koch et al. 2002), neurochemical, and clinical phenotypes (Eisenhofer et al. 1999). For instance, pheochromocytomas from patients with MEN2 produce epinephrine and its metabolite metanephrine, and have an adrenergic biochemical phenotype. However, pheochromocytomas from VHL patients produce almost exclusively norepinephrine and normetanephrine and have a noradrenergic phenotype (Eisenhofer et al. 1999, 2001). These differences in biochemical phenotype have been linked to underlying differences in the expression of tyrosine hydroxylase (TH), the rate-limiting enzyme in catecholamine production, and of phenylethanolamine $N$-methyltransferase (PNMT). Expression of PNMT, the enzyme that converts norepinephrine to epinephrine, is negligible in pheochromocytomas from VHL patients. The differences in biochemical phenotype are also reflected in the differences in catecholamine storage, transport, and release (Huynh et al. 2005). MEN2 pheochromocytomas have higher tumor concentrations of catecholamines, due to higher expression of TH, when compared with VHL pheochromocytomas. VHL pheochromocytomas appear to release catecholamines continuously, whereas MEN2 pheochromocytomas have an episodic release pattern. These differences in biochemical phenotype and release pattern help to explain differences in clinical manifestations of MEN2 and VHL pheochromocytomas. For example, MEN2 patients more often complain of symptoms occurring in attacks and are more often found to have paroxysmal hypertension, which can be contributed to episodic release of catecholamines (Ito et al. 1992). Pheochromocytomas of VHL and MEN2 patients may also be discriminated by their gene-expression profiles (Eisenhofer et al. 2004) as well as by distinctive patterns of expression of erythropoietin and its receptor (Vogel et al. 2005). The mechanisms underlying these differences are poorly understood.

Recently, we reported the use of two-dimensional gel electrophoresis (2-DGE) using microdissected tumor tissue to analyze protein patterns and proteins of two types of glioblastoma multiforms (Furuta et al. 2004). In this study, we employed a similar approach to investigate whether the differences between MEN2 and VHL pheochromocytomas could also be observed at the global protein expression level. Sequencing select target proteins that were differentially expressed in each type of pheochromocytoma, we aimed to gain insight into the mechanisms that may be responsible for these differences.

\section{Material and methods}

\section{Clinical material}

The study composed of 19 tumors: 8 pheochromocytomas of 5 patients with MEN2A (3 with bilateral tumors) and 11 pheochromocytomas of 9 patients with VHL (2 with bilateral tumors). The following mutations of the RET proto-oncogene were present in the MEN2A patients: C618S (one patient), C634R (three patients), and C634Y (one patient). One VHL patient had a partial deletion of the $V H L$ gene, the other VHL patients harbored the following missense mutations of the $v h l$ gene: $\mathrm{Y} 98 \mathrm{H}$ (two patients), Y112H (two patients), F136C (one patient), and R167Q (three patients). After surgical excision, tumors were immediately embedded in OCT (optimal cutting temperature compound), snap frozen in liquid nitrogen, and stored at $-80{ }^{\circ} \mathrm{C}$ until use. Eighteen cases came from the NIH and material of one patient with MEN2A was kindly provided by Dr Kvetnansky, Institute of Experimental Endocrinology, Slovak Academy of Sciences, Bratislava, Slovak Republic. Tumors were collected under studies that were approved by the appropriate Institutional Review Boards with informed consent obtained from all patients.

\section{Biochemical phenotype}

Measurements of tumor tissue concentrations of catecholamines were by liquid chromatography with electrochemical detection, as previously described (Eisenhofer et al. 1986).

\section{Tissue microdissection and 2-DGE analysis}

Selective tissue sampling for proteomic analysis was performed as described previously (Furuta et al. 2004) with the following minor modifications. From all tumor samples, a single $12 \mu \mathrm{m}$ thick section was taken and stained with $\mathrm{H} \& \mathrm{E}$ for histological evaluation. Tumor cell-rich ( $>90 \%$ tumors cells) areas that were not compromised by inflammation, necrosis, or stromal or endothelial proliferation were subsequently subjected to selective tumor dissection. Twelve micrometer thickness frozen sections were cut and the surrounding OCT was removed with a needle to collect $\sim 100000$ cells from each sample. Procurement of normal adrenal tissue, or areas of inflammation, necrosis, hemorrhage, or stromal or vascular proliferation were avoided.

2-DGE, followed by in-gel digestion, mass spectrometry, and protein identification were performed as previously described (Furuta et al. 2004). 


\section{Western blot analysis}

Serial $12 \mu \mathrm{m}$ thick sections of tissue were obtained from selected OCT embedded pheochromocytoma blocks. The OCT was removed and the tissue was immediately lysed in T-per tissue protein extraction reagent, containing $12 \mathrm{mM}$ bicine, $150 \mathrm{mM}$ sodium chloride ( $\mathrm{pH}$ 7.6; Pierce Biotechnology, Rockford, IL, USA) with a protease inhibitor cocktail tablet (Roche applied Science). Twenty micrograms of extracted protein were separated on an $8 \%$ Tris-glycine gel by SDS-PAGE and electroblotting to a polyvinylidene fluoride transfer membrane (Immobilon-P pvdf membrane, Millipore, Billerica, MA, USA) was performed. Nonspecific protein binding was blocked overnight using I-block (Tropix, Bedford, MA, USA) at $4{ }^{\circ} \mathrm{C}$. The membranes were then probed with chromogranin B (QED Bioscience Inc., San Diego, CA, USA catalog no. 26102 ), diluted in the ratio of $1: 400, \mathrm{TH}$ (MAB318, Chemicon), diluted in the ratio of 1:200 and $\beta$-actin monoclonal antibody at a dilution in the ratio of 1:500. Immunoblotting was performed using the Western-Star chemiluminescence detection system (Tropix Inc., Applied Biosciences, Foster City, CA, USA).

\section{Electron microscopy}

Tissue was prepared for electron microscopy, which was performed as previously described (Huynh et al. 2005).

\section{Results}

\section{Patient and tumor characteristics}

Nineteen tumors from 14 patients were analyzed, including 5 patients with MEN2 and 9 patients with VHL disease. From three MEN2 patients and two VHL patients with simultaneous bilateral disease, both tumors were analyzed. The patients' age at presentation ranged from 10 to 46 years (mean $=31$ years) and did not differ significantly between the VHL and MEN2 group. Patient and tumor characteristics are summarized in Table 1. All patients with MEN2 had an adrenergic neurochemical profile and all VHL patients had a noradrenergic neurochemical profile (Fig. 1).

Prior to 2-DGE analysis, the tumors were examined histologically on the H\&E to confirm the diagnosis of pheochromocytoma. Similar to previous reports (Koch et al. 2002), VHL-associated pheochromocytomas revealed many classical features including a thick tumor capsule, myxoid and hyalinized stroma, small to medium tumor cells intermixed with small vessels,
Table 1 Patient and tumor characteristics

\begin{tabular}{|c|c|c|}
\hline & $\begin{array}{c}\text { MEN2A (5 } \\
\text { patients, } 8 \text { tumors) }\end{array}$ & $\begin{array}{l}\text { VHL ( } 9 \text { patients, } \\
11 \text { tumors) }\end{array}$ \\
\hline Gender & $4 \mathrm{M}, 1 \mathrm{~F}$ & $6 \mathrm{M}, 3 \mathrm{~F}$ \\
\hline \multicolumn{3}{|c|}{ Age at presentation (years) } \\
\hline Median & 41 & 29 \\
\hline Range & $18-43$ & $10-46$ \\
\hline Neurochemical profile & Adrenergic & Noradrenergic \\
\hline
\end{tabular}

predominantly amphophilic and clear cytoplasm, and lack of nuclear atypia or mitoses (Fig. 2). In contrast, MEN2A-associated tumors demonstrated a thin capsule, vessels in the septae, large to medium size polygonal cells with eosinophilic granular cytoplasm, hyaline globules, and rare mitoses as well as extratumoral adrenal medullary hyperplasia (Fig. 2).

\section{Comparison of proteomic expression pattern}

The 2-DGE protein pattern was visually compared and revealed a highly consistent pattern for each group of tumors (VHL- or MEN2A-associated pheochromocytomas). However, the patterns between VHL- and MEN2A-associated tumors showed several differences (Fig. 3). Eight spots were unique or significantly overexpressed in VHL-associated pheochromocytoma and 15 spots were unique or significantly overexpressed in MEN2A-associated pheochromocytoma. Sequencing of protein spots was successful in seven MEN2A- and five VHL-associated proteins (Table 2). These included several housekeeping and structural proteins, as well as important functional and cell cycle proteins. One of the proteins identified in MEN2A tumors, but not VHL-related pheochromocytomas, was chromogranin B.

\section{Validation of differentially expressed protein}

To validate the differential expression of the proteins detected by 2-DGE proteomic pattern comparison by

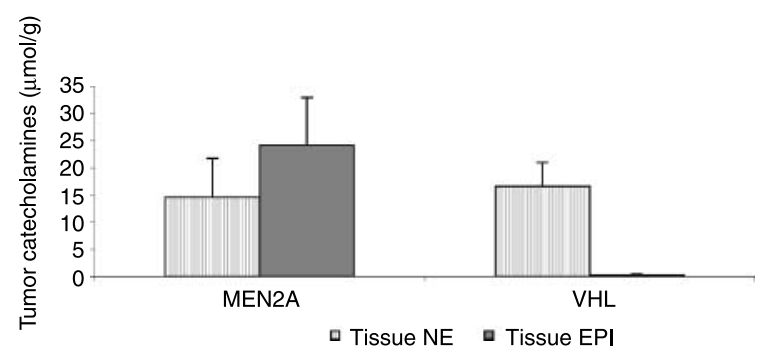

Figure 1 Mean tumor catecholamines for MEN2A and VHL pheochromocytomas. NE, norepinephrine; EPI, epinephrine. All values are mean \pm S.E.M. 

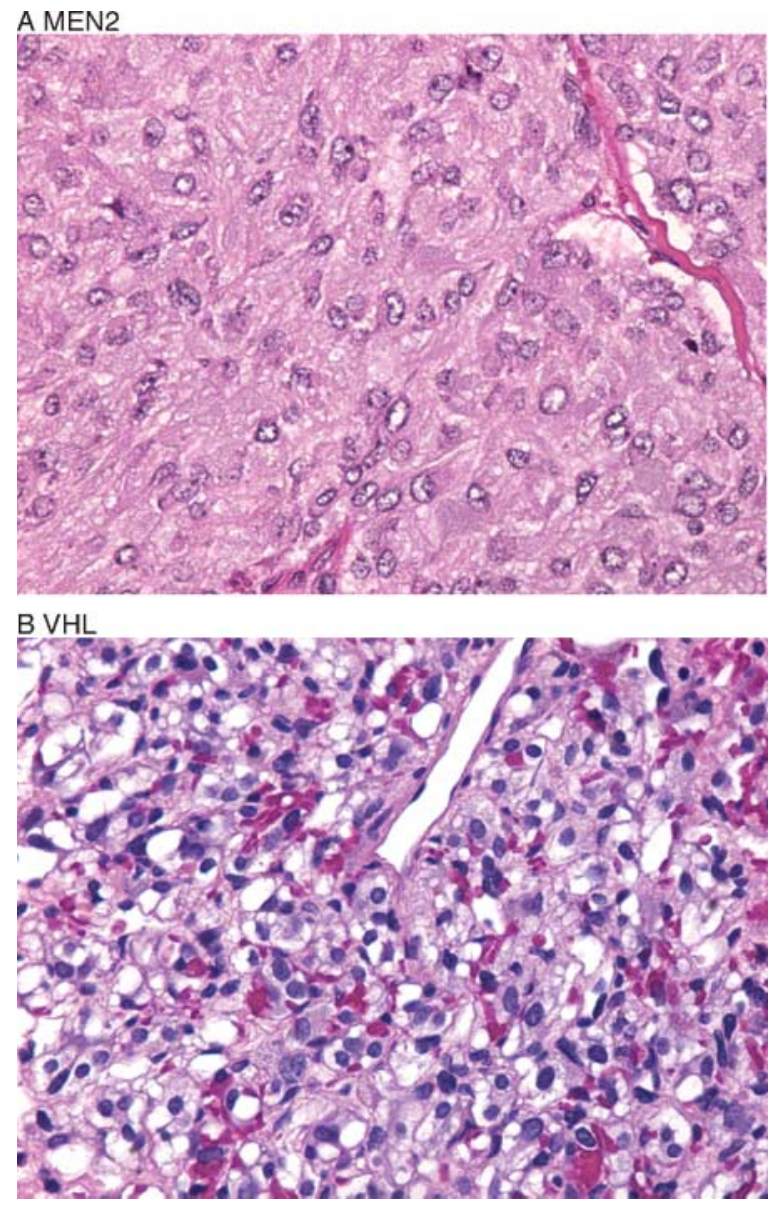

Figure 2 Representative histopathology of MEN2A- (A) and VHL-associated (B) pheochromocytoma (H\&E stain, $\times 400)$. A MEN2A tumor demonstrates polygonal, large to medium size cells with eosinophilic granular cytoplasm and vessels in the septae. In contrast, a VHL-associated pheochromocytoma reveals small to medium size tumor cells with amphophilic and clear cytoplasm and intermixed small vessels.

western blot we selected chromogranin B, as its expression had been documented in pheochromocytoma in prior studies, but with no consideration of the patient's genetic background (Lloyd et al. 1988, Weiler et al. 1988, Portela-Gomes et al. 2004). Tissue samples from five MEN2A- and five VHL-associated pheochromocytomas were investigated for expression of chromogranin B. For comparison, we also evaluated $\mathrm{TH}$ by western blot, as it is known to have higher expression in MEN2- than VHL-related tumors. In accordance with prior experiments, TH was found to be expressed in all investigated pheochromocytoma samples, with a higher amount of TH in MEN2Aassociated tumors than VHL-associated tumors at comparable levels of $\beta$-actin. In contrast, chromogranin B was completely absent in VHL-associated pheochromocytomas, while abundantly expressed in all MEN2A-associated tumors (Fig. 4). As chromogranins are implicated in the formation of secretory granules, we looked at granules at the ultrastructural level in two representative tumors. In agreement with prior studies (Eisenhofer et al. 2001, Huynh et al. 2005), we observed that pheochromocytoma tumor cells from VHL patients contained fewer granules than MEN2A tumor cells (Fig. 5).

\section{Discussion}

Pheochromocytomas associated with VHL disease and MEN2 differ significantly in their clinical (Aprill et al. 1994, Pomares et al. 1998), histopathological (Koch et al. 2002), and neurochemical (Eisenhofer et al. 1999, 2001, Huynh et al. 2005) phenotype. In this study, we show that they also have distinct protein patterns. The biological basis for these differences has yet to be found, as different underlying genetic mechanisms for both tumor syndromes cannot fully explain such differences. For MEN2-associated pheochromocytomas, the underlying genetic basis is an activating mutation in a hot spot area of the RET protooncogene (Huang et al. 2000). This mutation leads to activation of the RET receptor, a plasma membranebound tyrosine kinase, which is expressed by neuroendocrine and neural cells. The molecular basis of VHL disease is different. Biallelic inactivation of the VHL tumor suppressor gene leads to stabilization of hypoxia inducible factor (HIF) under normoxic conditions with subsequent upregulation of hypoxic response, including vascular endothelial growth factor and erythropoietin. Although the molecular dysregulations that are caused by the respective mutations are well understood, it remains unclear how these genetic mechanisms could lead to the different phenotypes of VHL- and MEN2-associated pheochromocytomas.

\section{Distinct protein patterns in MEN2- and VHL- associated pheochromocytoma}

In this study, we compared the proteomic expression profiles of selectively procured populations of microdissected MEN2A- and VHL-related pheochromocytoma tumor cells by 2-DGE and detected significant differences in the protein expression patterns. In a previous study, gene expression patterns of VHL- and MEN2-associated pheochromocytomas were compared using DNA microarray analysis (Eisenhofer et al. 2004). A high number of genes were found to be overexpressed in VHL-associated tumors. In general, these were genes linked to the hypoxia pathway. In the 


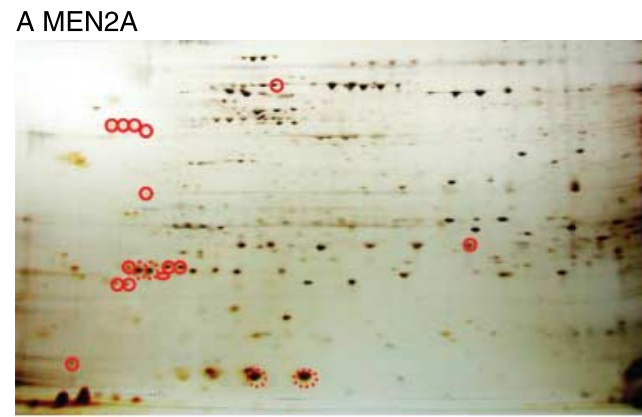

B VHL

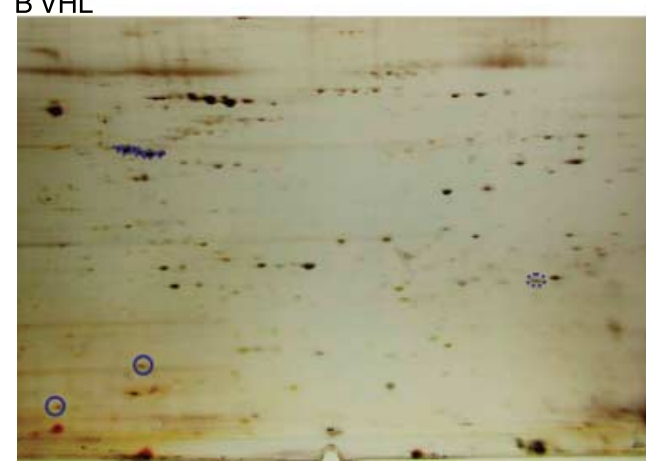

Proteins significantly unique for (continues circles) or overexpressed in (dashed circles) MEN2 (top) or VHL (bottom)
A MEN2A
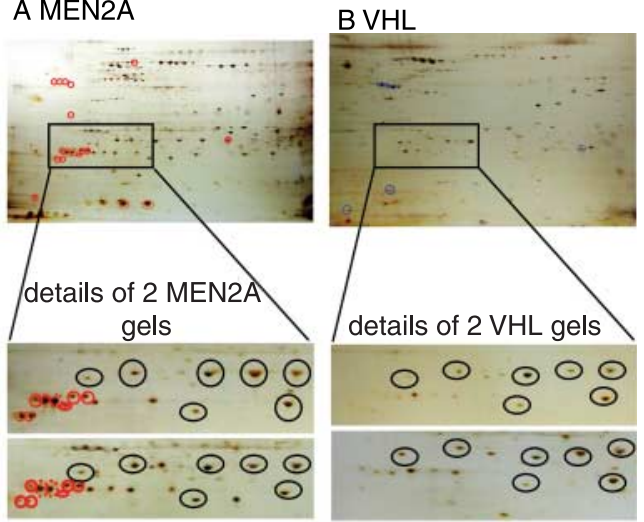

Proteins in common between MEN2 and VHL

- Proteins significantly overexpressed in or unique for MEN2

Figure 3 Representative examples of two-dimensional gel electrophoresis protein patterns for MEN2A- and VHL-associated pheochromocytomas. (A) Comparison of protein expression pattern reveals several common proteins but also distinct differences. Some proteins are unique or significantly overexpressed in one of the pheochromocytoma entities. (B) Enlargements depicting the same area in two MEN2A gels and two VHL gels.

present study, we identified several differentially expressed proteins by sequencing of protein spots that are unique for each tumor entity. Our findings confirm and extend previous observations, which suggested that fundamental differences separate VHL- and MEN2-associated pheochromocytomas. For example, VHL-associated tumors expressed more heat shock protein, a finding that may be explained by the increased hypoxic response in these tumors caused by HIF stabilization. Furthermore, among the proteins which are uniquely expressed in MEN2-associated tumors, there are two that have been associated with malignancy. These are a DNA-binding domain of the Wilms tumor gene (WTI) and a DNA-activated protein kinase. Such proteins could play an important role in the growth of MEN2 pheochromocytoma cells. In contrast, VHL tumors did not have these malignancyassociated proteins.

\section{VHL-associated pheochromocytoma may lack the machinery for catecholamine storage}

Among the differentially expressed proteins identified, we selected chromogranin B for further validation as its expression has been studied in pheochromocytoma previously (Lloyd et al. 1988, Weiler et al. 1988, Portela-Gomes et al. 2004). However, these prior studies did not investigate pheochromocytomas from different genetic backgrounds. By western blotting, we confirmed that chromogranin $\mathrm{B}$ is exclusively expressed by MEN2A- but not VHL-associated pheochromocytomas. Chromogranin B is a secretory granule matrix protein from the chromogranin/secretogranin family, which represents water soluble, acidic glycoproteins present in almost all endocrine, neuroendocrine and neuronal tissues (see Taupenot et al. (2003) for review). In the adrenal medulla, all three chromogranins $(\mathrm{A}-\mathrm{C})$ have been found (Wiedenmann et al. 1988, Winkler \& Fischer-Colbrie 1992). Chromogranins A and B are thought to contribute to the formation of secretory granules (Kim et al. 2001, Huh et al. 2003). The chromogranins are stored within the secretory granules containing peptide hormones and catecholamines. Upon stimulation, the chromogranins are released together with the catecholamines and neuropeptides from the cells of the adrenal medulla and sympathetic nervous system. Two previous studies reported elevated serum levels of chromogranin A (Hsiao et al. 1990), and chromogranins 
Table 2 Differentially expressed protein in von Hippel-Lindau (VHL)- versus multiple endocrine neoplasia type 2 (MEN2A)associated pheochromocytomas identified by comparative proteomic profiling followed by sequencing

\begin{tabular}{|c|c|c|c|}
\hline Number & Protein & Location & Potential biological function \\
\hline \multicolumn{4}{|l|}{ MEN2A } \\
\hline 1 & Chromogranin B & 20p12.3 & $\begin{array}{l}\text { Neuroendocrine secretory granule protein, which may } \\
\text { be the precursor for other biologically active } \\
\text { peptides }\end{array}$ \\
\hline 2 & LDL receptor related protein 1 & $12 q 13-14$ & $\begin{array}{l}\text { Involved in the plasma clearance of chylomicron } \\
\text { remnants and activated } \alpha 2 \text {-macroglobulin, as well } \\
\text { as the local metabolism of complexes between } \\
\text { plasminogen activators and their endogenous } \\
\text { inhibitors }\end{array}$ \\
\hline 3 & Nebulin & $2 q 22$ & $\begin{array}{l}\text { This giant muscle protein may be involved in } \\
\text { maintaining the structural integrity of sarcomeres } \\
\text { and the membrane system associated with the } \\
\text { myofibrils. Bind and stabilize F-actin }\end{array}$ \\
\hline 4 & RGR protein & $10 q 23$ & $\begin{array}{l}\text { Receptor for all-trans-and 11-cis-retinal. Binds pre- } \\
\text { ferentially to the former and may catalyze the } \\
\text { isomerization of the chromophore by a retino- } \\
\text { chrome-like mechanism }\end{array}$ \\
\hline 5 & A-kinase anchor protein 9 & $6 q 23$ & $\begin{array}{l}\text { Probably, targets cAMP-dependent protein kinase } \\
\text { (PKA) to the cellular membrane or cytoskeletal } \\
\text { structures }\end{array}$ \\
\hline 6 & WT1 & & Potential role in transcriptional regulation \\
\hline 7 & DNA-activated protein kinase & & $\begin{array}{l}\text { Serine/threonine-protein kinase involved in DNA } \\
\text { nonhomologous end joining (NHEJ) required for } \\
\text { double-strand break repair and } \mathrm{V}(\mathrm{D}) \mathrm{J} \text { recombina- } \\
\text { tion. Involved in modulation of transcription }\end{array}$ \\
\hline \multicolumn{4}{|l|}{ VHL } \\
\hline 1 & Heat shock protein 5 (70 kDa) & $9 q 33-34$ & $\begin{array}{l}\text { Probably plays a role in facilitating the assembly of } \\
\text { multimeric protein complexes inside the ER }\end{array}$ \\
\hline 2 & BiP protein & & Heat shock protein \\
\hline 3 & Urotensin II & $1 p 36$ & Highly potent vasoconstrictor \\
\hline 4 & Ubiquitin thiolesterase L1 & $4 p 14$ & $\begin{array}{l}\text { Ubiquitin-protein hydrolase is involved both in the } \\
\text { processing of ubiquitin precursors and of ubiqui- } \\
\text { nated proteins }\end{array}$ \\
\hline 5 & Triosephosphate isomerase & $12 \mathrm{p} 13$ & Glycolysis \\
\hline
\end{tabular}

A-C (Stridsberg \& Husebye 1997) in patients with familial and sporadic pheochromocytoma. This is the first report of a differential expression of chromogranin B in VHL- and MEN2A-associated pheochromocytomas. If the differential expression of chromogranin $\mathrm{B}$ is associated with differential serum levels, it could be used in the development of a diagnostic chromogranin B ELISA for clinical use. Since chromogranin B has been suggested to be involved in the formation of secretory vesicles (Huh et al. 2003), we investigated the morphology of these vesicles by electron microscopy. Consistent with previous findings (Eisenhofer et al. 1999, Huynh et al. 2005), we observed that pheochromocytoma tumor cells from VHL patients contained fewer granules than MEN2A tumor cells, which might be related to the absence of chromogranin B in VHL pheochromocytomas. These findings suggest that VHL-associated pheochromocytoma lacks machinery for catecholamine storage.
Distinct proteomic, biochemical, and phenotypic profiles suggest differences in cellular origins of MEN2- and VHL-associated pheochromocytomas

Our study confirms and expands the evidence for fundamental differences between the two tumor entities, showing that, unlike MEN2A pheochromocytomas,

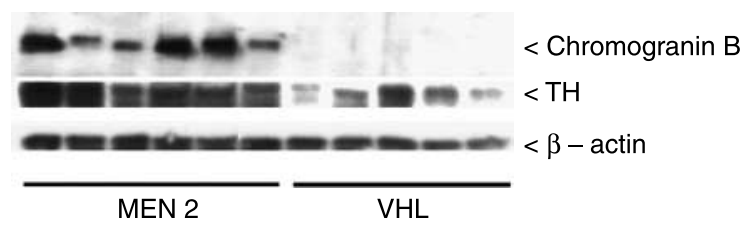

Figure 4 Western blot reveals differential expression for chromogranin B and TH in VHL- versus MEN2A-associated pheochromocytomas. $\mathrm{TH}(59 \mathrm{kDa})$ is expressed at significantly lower levels in VHL-associated tumors at equal protein amounts indicated by equal intensity of $\beta$-actin. The band for chromogranin $\mathrm{B}(78 \mathrm{kDa})$ is strong in all MEN2A tumors but completely absent in VHL-associated pheochromocytomas. 

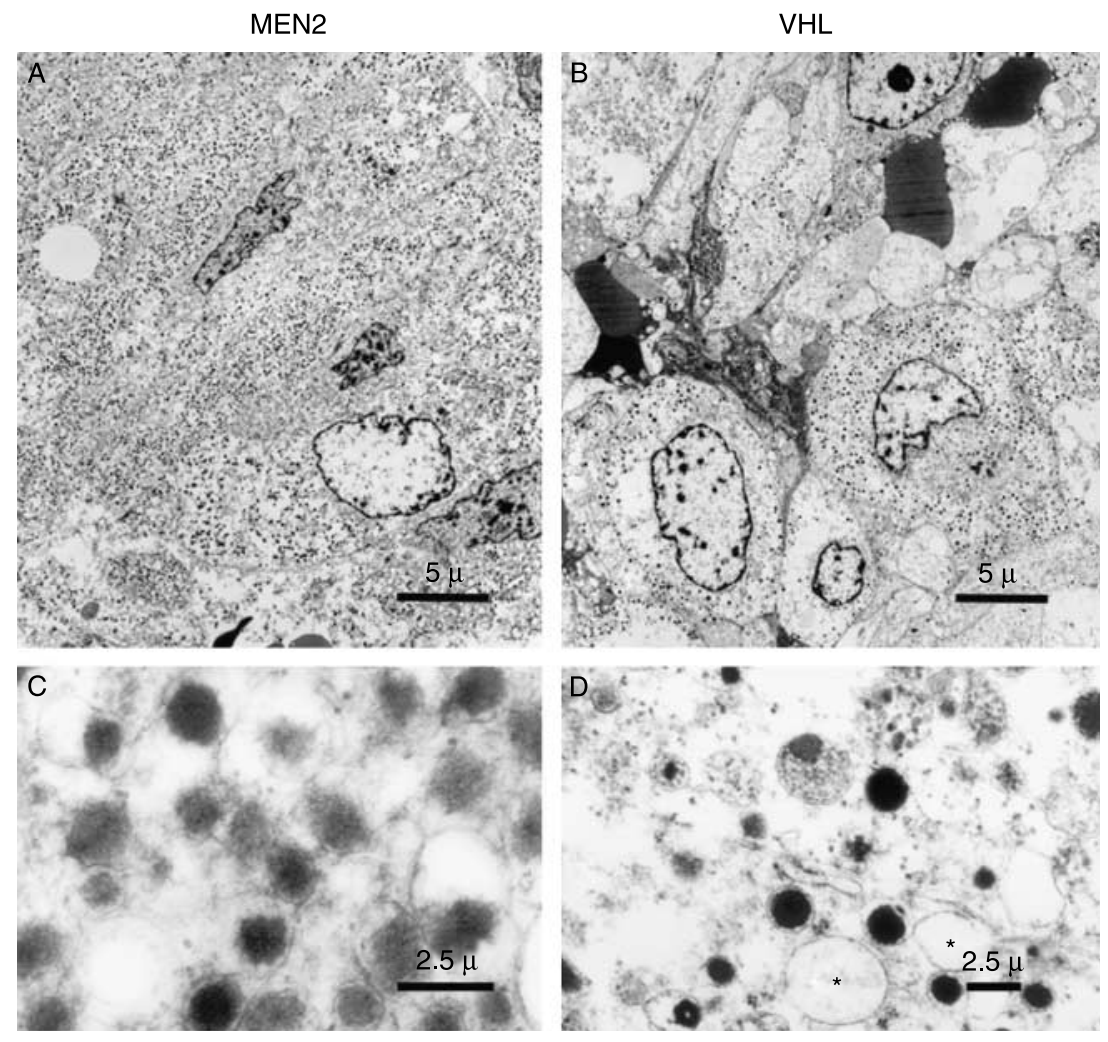

Figure 5 Electron microscopy micrographs of pheochromocytoma tissue in MEN2A (A and C) and VHL (B and D). MEN2Aassociated pheochromocytomas show higher number of secretory granules per cell than VHL-associated pheochromocytomas. Granules vary in their size, as well as core density and location (centric versus acentric). (D) Two empty granules (*).

VHL-associated pheochromocytomas lack chromogra$\operatorname{nin} \mathrm{B}$, a protein involved in secretory vesicle formation. Combined with the low levels of $\mathrm{TH}$, the rate-limiting enzyme of catecholamines synthesis, our data imply that VHL-associated pheochromocytomas may be deficient in essential components of the machinery of catecholamine-producing cells.

Recently, a common pathway has been suggested for the development of pheochromocytomas in hereditary syndromes (Lee et al. 2005a). The authors propose that germline mutations in VHL, c-RET, SDH, and NFI allow sympathetic neuronal precursor cells to escape from developmental apoptosis through dysregulation of NGF signaling. This suggested common pathway, however, still leaves the following question unanswered: why would tumors that arise through such a shared mechanism have such distinct histopathological, ultrastructural, biochemical, and clinical characteristics and show such different expression profiles both at gene and protein levels? We propose two possible explanations: 1) pheochromocytomas in MEN2 and VHL syndrome may derive from two different types of precursor cells; or 2) they may derive from the same precursor cell arrested at different stages of embryonic development.

The possibility of a different precursor cell of origin for MEN2A and VHL adrenal tumors is supported by a recent study showing coexpression of erythropoietin and its receptor in VHL-associated pheochromocytomas (Vogel et al. 2005). The same autoendocrine mechanism has also been shown for VHL-associated renal cell carcinoma (Lee et al. 2005b) and hemangioblastoma, with a developmentally arrested angioblastic lineage found in the latter tumor (Vortmeyer et al. 2003). In contrast, erythropoietin and its receptor are not expressed in MEN2A-associated pheochromocytomas (Vogel et al. 2005).

Similarities between both MEN2 and VHL pheochromocytomas, such as the production of catecholamines, may result from an influence of the local microenvironment of adrenal medulla on the different precursor cells. Though the adrenal medulla microenvironment may stimulate the precursor cells from VHL tumors to develop certain features in common with MEN2 pheochromocytomas through gene-induction, we hypothesize that the effect of epigenetics and the local 
environment on these cells is insufficient for them to develop all components of catecholamine biosynthesis.

In summary, we propose that VHL-associated pheochromocytomas have a different pathogenesis than MEN2-associated tumors. VHL adrenal tumors may derive from developmentally arrested precursor cells similar to those identified in other VHLassociated tumors, such as central nervous system hemangioblastomas, renal cell carcinomas, and endolymphatic sac tumors. Within the local environment of the adrenal gland, some pheochromocytoma-specific genes or proteins, such as $\mathrm{TH}$, may be activated or de-repressed in these genetically defined precursor cells, while others, such as chromogranin B, may not be inducible in VHL precursor cells. Importantly, VHL cells still retain other gene characteristics, such as expression of erythropoietin and its receptor, and histological characteristics (clear cell phenotype and vascular architecture) that are common to all VHL disease-associated tumors but are not found in MEN2associated tumors. These differences underscore the importance of the unique histopathological, neurochemical, and clinical features of pheochromocytomas in patients with VHL and MEN2 disease and point to a divergent pathogenesis, possibly at the level of developmentally arrested precursor cells.

\section{Acknowledgements}

This work was supported by the intramural program of the National Institute of Child Health and Human Development, the National Institute of Neurological Disorders and Stroke, and the National Cancer Institute, NIH. The authors declare that there is no conflict of interest that would prejudice the impartiality of this scientific work.

\section{References}

Aprill BS, Drake AJ III, Lasseter DH \& Shakir KM 1994

Silent adrenal nodules in von Hippel-Lindau disease suggest pheochromocytoma. Annals of Internal Medicine 120 485-487.

Bryant J, Farmer J, Kessler LJ, Townsend RR \& Nathanson KL 2003 Pheochromocytoma: the expanding genetic differential diagnosis. Journal of the National Cancer Institute 95 1196-1204.

Eisenhofer G, Goldstein DS, Stull R, Keiser HR, Sunderland T, Murphy DL \& Kopin IJ 1986 Simultaneous liquidchromatographic determination of 3,4-dihydroxyphenylglycol, catecholamines, and 3,4-dihydroxyphenylalanine in plasma, and their responses to inhibition of monoamine oxidase. Clinical Chemistry 32 2030-2033.
Eisenhofer G, Lenders JW, Linehan WM, Walther MM, Goldstein DS \& Keiser HR 1999 Plasma normetanephrine and metanephrine for detecting pheochromocytoma in von Hippel-Lindau disease and multiple endocrine neoplasia type 2. New England Journal of Medicine 340 1872-1879.

Eisenhofer G, Walther MM, Huynh T-T, Li S-T, Bornstein SR, Vortmeyer A, Mannelli M, Goldstein DS, Linehan WM, Lenders JWM et al. 2001 Pheochromocytomas in von Hippel-Lindau syndrome and multiple endocrine neoplasia type 2 display distinct biochemical and clinical phenotypes. Journal of Clinical Endocrinology and Metabolism 86 1999-2008.

Eisenhofer G, Huynh TT, Pacak K, Brouwers FM, Walther MM, Linehan WM, Munson PJ, Mannelli M, Goldstein DS \& Elkahloun AG 2004 Distinct gene expression profiles in norepinephrine- and epinephrine-producing hereditary and sporadic pheochromocytomas: activation of hypoxia-driven angiogenic pathways in von Hippel-Lindau syndrome. Endocrine-Related Cancer 11 897-911.

Furuta M, Weil RJ, Vortmeyer AO, Huang S, Lei J, Huang TN, Lee YS, Bhowmick DA, Lubensky IA, Oldfield EH et al. 2004 Protein patterns and proteins that identify subtypes of glioblastoma multiforme. Oncogene 23 6806-6814.

Hsiao RJ, Neumann HP, Parmer RJ, Barbosa JA \& O'Connor DT 1990 Chromogranin A in familial pheochromocytoma: diagnostic screening value, prediction of tumor mass, and post-resection kinetics indicating two-compartment distribution. American Journal of Medicine $\mathbf{8 8}$ 607-613.

Huang SC, Koch CA, Vortmeyer AO, Pack SD, Lichtenauer UD, Mannan P, Lubensky IA, Chrousos GP, Gagel RF, Pacak K et al. 2000 Duplication of the mutant RET allele in trisomy 10 or loss of the wild-type allele in multiple endocrine neoplasia type 2-associated pheochromocytomas. Cancer Research $606223-6226$.

Huh YH, Jeon SH \& Yoo SH 2003 Chromogranin B-induced secretory granule biogenesis: comparison with the similar role of chromogranin A. Journal of Biological Chemistry 278 40581-40589.

Huynh TT, Pacak K, Brouwers FM, Abu-Asab MS, Worrell RA, Walther MM, Elkahloun AG, Goldstein DS, Cleary S \& Eisenhofer G 2005 Different expression of catecholamine transporters in phaeochromocytomas from patients with von Hippel-Lindau syndrome and multiple endocrine neoplasia type 2 . European Journal of Endocrinology 153 551-563.

Ito Y, Fujimoto Y \& Obara T 1992 The role of epinephrine, norepinephrine, and dopamine in blood pressure disturbances in patients with pheochromocytoma. World Journal of Surgery 16 759-763.

Kim T, Tao-Cheng JH, Eiden LE \& Loh YP 2001 Chromogranin A, an "on/off" switch controlling dense-core secretory granule biogenesis. Cell $\mathbf{1 0 6}$ 499-509. 
Koch CA, Mauro D, Walther MM, Linehan WM, Vortmeyer AO, Jaffe R, Pacak K, Chrousos GP, Zhuang Z \& Lubensky IA 2002 Pheochromocytoma in von Hippel-Lindau disease: distinct histopathologic phenotype compared to pheochromocytoma in multiple endocrine neoplasia type 2. Endocrine Pathology 13 17-27.

Lee S, Nakamura E, Yang H, Wei W, Linggi MS, Sajan MP, Farese RV, Freeman RS, Carter BD, Kaelin WG, Jr et al. $2005 a$ Neuronal apoptosis linked to EglN3 prolyl hydroxylase and familial pheochromocytoma genes: developmental culling and cancer. Cancer Cell $\mathbf{8}$ 155-167.

Lee YS, Vortmeyer AO, Lubensky IA, Vogel TW, Ikejiri B, Ferlicot S, Benoit G, Giraud S, Oldfield EH, Linehan WM et al. $2005 b$ Coexpression of erythropoietin and erythropoietin receptor in von Hippel-Lindau disease-associated renal cysts and renal cell carcinoma. Clinical Cancer Research 11 1059-1064.

Lenders JW, Eisenhofer G, Mannelli M \& Pacak K 2005 Phaeochromocytoma. Lancet 366 665-675.

Lloyd RV, Cano M, Rosa P, Hille A \& Huttner WB 1988 Distribution of chromogranin A and secretogranin I (chromogranin B) in neuroendocrine cells and tumors. American Journal of Pathology 130 296-304.

Neumann HP, Bausch B, McWhinney SR, Bender BU, Gimm O, Franke G, Schipper J, Klisch J, Altehoefer C, Zerres K et al. 2002a Germ-line mutations in nonsyndromic pheochromocytoma. New England Journal of Medicine 346 1459-1466.

Neumann HP, Hoegerle S, Manz T, Brenner K \& Iliopoulos O $2002 b$ How many pathways to pheochromocytoma? Seminars in Nephrology 22 89-99.

Pomares FJ, Canas R, Rodriguez JM, Hernandez AM, Parrilla P \& Tebar FJ 1998 Differences between sporadic and multiple endocrine neoplasia type 2A phaeochromocytoma. Clinical Endocrinology 48 195-200.

Portela-Gomes GM, Stridsberg M, Grimelius L, Falkmer UG \& Falkmer S 2004 Expression of chromogranins A, B, and
C (secretogranin II) in human adrenal medulla and in benign and malignant pheochromocytomas. An immunohistochemical study with region-specific antibodies. Apmis 112 663-673.

Riccardi VM 1981 Von Recklinghausen neurofibromatosis. New England Journal of Medicine 305 1617-1627.

Stridsberg M \& Husebye ES 1997 Chromogranin A and chromogranin B are sensitive circulating markers for phaeochromocytoma. European Journal of Endocrinology 136 67-73.

Taupenot L, Harper KL \& O'Connor DT 2003 The chromogranin-secretogranin family. New England Journal of Medicine 348 1134-1149.

Vogel TW, Brouwers FM, Lubensky IA, Vortmeyer AO, Weil RJ, Walther MM, Oldfield EH, Linehan WM, Pacak K \& Zhuang Z 2005 Differential expression of erythropoietin and its receptor in von Hippel-Lindau-associated and multiple endocrine neoplasia type 2-associated pheochromocytomas. Journal of Clinical Endocrinology and Metabolism 90 3747-3751.

Vortmeyer AO, Frank S, Jeong SY, Yuan K, Ikejiri B, Lee YS, Bhowmick D, Lonser RR, Smith R, Rodgers G et al. 2003 Developmental arrest of angioblastic lineage initiates tumorigenesis in von Hippel-Lindau disease. Cancer Research 63 7051-7055.

Weiler R, Fischer-Colbrie R, Schmid KW, Feichtinger H, Bussolati G, Grimelius L, Krisch K, Kerl H, O’Connor D \& Winkler H 1988 Immunological studies on the occurrence and properties of chromogranin A and B and secretogranin II in endocrine tumors. American Journal of Surgical Pathology 12 877-884.

Wiedenmann B, Waldherr R, Buhr H, Hille A, Rosa P \& Huttner WB 1988 Identification of gastroenteropancreatic neuroendocrine cells in normal and neoplastic human tissue with antibodies against synaptophysin, chromogranin A, secretogranin I (chromogranin B), and secretogranin II. Gastroenterology 95 1364-1374.

Winkler H \& Fischer-Colbrie R 1992 The chromogranins A and B: the first 25 years and future perspectives.

Neuroscience 49 497-528. 